\title{
NOTE
}

\section{Boron determinations of silicate reference rocks by the isotope dilution method in a high-background environment}

\author{
SHUN'ICHI NAKAI* \\ Earthquake Research Institute, The University of Tokyo, Yayoi 1-1-1, Bunkyo-ku, Tokyo 113-0032, Japan
}

(Received August 28, 2020; Accepted November 7, 2020)

\begin{abstract}
Boron concentrations in silicate reference rocks were determined using an inductively coupled plasma mass spectrometer (ICP-MS) installed in a laboratory with a high background noise level of boron. The feasibility of three methods of internal standard, standard addition, and isotope dilution were examined. Application of the internal standard analysis is difficult in the absence of an appropriate internal standard element. Repeated analyses of the reference rocks showed that the isotope dilution analysis yielded more reproducible concentrations than the standard addition analysis in the high background environment. Results of boron determinations of 12 standard silicate rocks using the isotope dilution method were mostly consistent with values reported earlier from wet chemical analysis and from prompt gamma ray neutron activation analysis. The isotope dilution method can be recommended for boron determination.
\end{abstract}

Keywords: background, boron, ICP-MS, isotope dilution, reference rock

\section{INTRODUCTION}

Altered oceanic crust and sea floor sediments are rich in boron. It is transferred with fluid phase squeezed by dehydration processes of a subducting slab. Subductionrelated volcanic rocks are rich in boron compared with Mid-Ocean-Ridge basalts and volcanic rocks related to intra-plate volcanism. Consequently, boron is used as a tracer to assess contributions of subduction fluids in arc environments (Sano et al., 2001; and references therein). Although boron has been determined using inductively coupled plasma-atomic emission spectrometry (Ryan and Langmuir, 1993), inductively coupled plasma mass spectrometry (Makishima et al., 1997; Nagaishi and Ishikawa, 2009), thermal ionization mass spectrometry combined with isotope dilution analysis (Ishikawa and Nakamura, 1992), and secondary ionization mass spectrometry (Chaussidon and Jambon, 1994), the loss of volatile boron and contamination from the laboratory environment have persisted as obstacles that hinder determination of boron concentrations through wet chemical analyses. Prompt gamma ray neutron activation analysis (PGNAA) has been used for boron determination since the 1990s. This method can avoid the two difficulties explained above because it requires no chemical handling

*E-mail address: snakai@eri.u-tokyo.ac.jp

Copyright $@ 2021$ by The Geochemical Society of Japan. of rock samples (Yonezawa et al., 1999; Sano et al., 1998, 1999, 2001; Miyoshi et al., 2010; Shinjoe et al., 2013). Sano et al. (1998, 1999) reported that relative standard deviations (\% RSD) of replicate analyses of standard rocks were better than $5 \%$ for the wide range of boron concentrations of 8-160 ppm. After the nuclear power plant accident in 2011, neutron radiation experiments were halted in Japan.

Boron determination was attempted in a high background environment in this study. An ICP-MS used for boron determinations was installed in a laboratory where laser ablation ICP mass spectrometry analyses on glass bead samples fused with $\mathrm{LiBO}_{4}$ was conducted with another ICP-MS. The author investigated effective methods to reduce the influence of a high background on boron peaks.

Three analytical methods were compared to improve the accuracy of boron determination. When the concentration of an element is measured using a sensitivity method that compares a signal intensity of an element in a sample solution with that in a standard solution, an internal standard element is often doped to the sample solution to correct the influence of the sample-derived matrix. The internal standard element is selected from elements that are not included in the sample solution and which have a similar mass number to that of the element to be analyzed. Finding a suitable internal standard element is difficult when light elements such as $\mathrm{Li}, \mathrm{Be}$, and $\mathrm{B}$ in silicate rock samples are determined. Gotan et al. 
Table 1. ICP-MS operating conditions

\begin{tabular}{ll}
\hline ICP Ion Source & \\
RF power & $1.4 \mathrm{~kW}$, frequency $27.12 \mathrm{MHz}$ \\
Torch & Fassel type, made of quartz glass \\
Plasma Ar flow rate & $14 \mathrm{~L} / \mathrm{min}$ \\
Auxiliary Ar flow rate & $0.8 \mathrm{~L} / \mathrm{min}$ \\
Nebulizer Ar flow rate & $0.98 \mathrm{~L} / \mathrm{min}$ (typical) \\
Collision gas He flow rate & $6.0 \mathrm{~mL} / \mathrm{min}$ \\
Nebulizer & Concentric type, Teflon \\
Spray chamber & Conical type, quartz glass (cooled to $3{ }^{\circ} \mathrm{C}$ by a Peltier cooler) \\
Solution uptake rate & $0.25 \mathrm{~mL} /$ min (auto-aspiration) \\
& \\
Interface & Pt tip insert in a Ni base, $1.1 \mathrm{~mm}$ diameter orifice \\
Sample cone & Pt tip insert in a Ni base, $0.9 \mathrm{~mm}$ diameter orifice \\
Skimmer cone & \\
& \\
Data Acquisition & Peak jumping \\
Acquisition mode & Pulse counting mode points/peak 5 \\
Detection mode & $10 \mathrm{~ms} /$ isotope \\
Dwell time & $2200 \mathrm{~ms} /$ isotope \\
Integration time & 3 times \\
Replication & \\
\hline
\end{tabular}

(2008) reported that the In internal standardization yielded more than $10 \%$ lower Be concentrations than that determined using the standard addition method and the column separation method. Nagaishi and Ishikawa (2009) used Be as an internal standard element for B analyses, taking advantage of the low sensitivity for Be of the ICPMS used in their study. Mori et al. (2007) used a mixture of internal standard elements composed of Ge, In, Tm, and Bi for B determinations. Liu et al. (2019) used Rh as an internal standard element. The feasibility of Be internal standardization was examined for the ICP-MS used for this study. The author also examined methods of standard addition and isotope dilution to test the accuracy and reproducibility of boron concentration determinations. Application of isotope dilution inductively coupled plasma mass spectrometry to boron determination was first reported by Makishima et al. (1997). This method can reduce difficulties of volatile boron loss. Results of boron determination obtained when using the three methods are compared: the author analyzed 12 standard rocks and compared the results with earlier reported values obtained using wet chemical analyses and PGNAA analysis.

\section{ANAlytical TeChNiQues}

\section{Instrumentation and reagents}

The ICP-MS used for this study (X-series 2; ThermoFischer Scientific, USA) was installed at the Earthquake Research Institute, The University of Tokyo, Japan. This instrument is equipped with a collision cell. Operating conditions are presented in Table 1. Typical sensitivity for ${ }^{11} \mathrm{~B}$ in this study was $1400 \mathrm{cps} / \mathrm{ppb}$.

All solutions used for this study were prepared using purified $18 \mathrm{M} \Omega \cdot \mathrm{cm} \mathrm{H}_{2} \mathrm{O}$ produced using a Milli-Q Element system (Millipore Corp., USA). The Milli-Q water was purified with resin of AmberSep ${ }^{\text {TM }}$ IRA743 (Rohm and Haas Co., USA), which removes boron from water. Commercially supplied high-purity reagents of $\mathrm{HF}, \mathrm{HCl}$, and $\mathrm{HNO}_{3}$ (TAMAPURE AA-100; Tama Chemicals Co. Ltd, Japan) were used for this study. A $1 \%$ mannitol solution was prepared by dissolving mannitol powder (Merck and Co. Inc., Germany) in 0.015 M HF. The 0.015 M HF/ $0.15 \mathrm{M} \mathrm{HNO}_{3}$ acid mixture was used for diluting sample solutions and also as a sample washing-out solution during ICP-MS analyses.

A boron atomic absorption standard (Kanto Chemical Co. Inc., Japan) was used as a concentration standard. Also, SRM 981 (NIST, USA) was used as an isotope ratio standard. ISOT-B10 (Spex Industries Inc., USA) enriched in ${ }^{10} \mathrm{~B}$ was used as a spike for isotope dilution analysis. Isotope abundances of ${ }^{10} \mathrm{~B}$ and ${ }^{11} \mathrm{~B}$ were measured as $0.9709 \pm 0.0002$ and $0.0291 \pm 0.0002$, respectively, which is close to the ICP-MS measured values of 0.973 and 0.0271 reported by Spex Industries Inc. ISOT$\mathrm{B} 10$ was diluted to around $0.5 \mathrm{ppm}$ using a $0.015 \mathrm{M} \mathrm{HF} /$ $0.15 \mathrm{M} \mathrm{HNO}_{3}$ acid solution. The spike solution concentration was calibrated by the inverse isotope dilution with the boron atomic absorption standard.

\section{Sample preparations}

For isotope dilution analyses, 20-40 mg of rock powder was weighed in a 25-mL screw-top PFA vial (Savillex Corp., USA). Samples were spiked with appropriate 


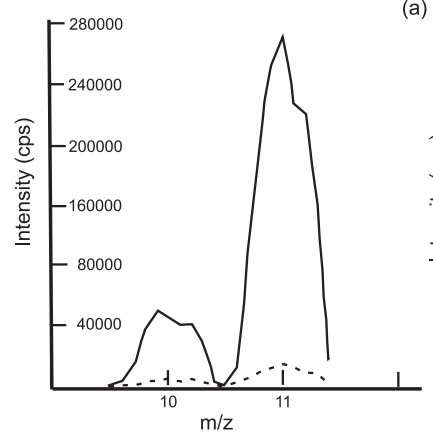

(a)

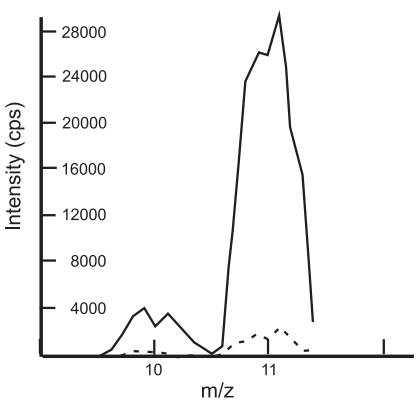

Fig. 1. Mass spectra from $\mathrm{m} / z=9.5$ to $\mathrm{m} / \mathrm{z}=11.4$, obtained for a 20 ppb boron solution (solid line) and a blank solution (dotted line) without (a) and with (b) addition of He collision gas. It is noteworthy that tailing of the ${ }^{12} C^{+}$peak on the ${ }^{11} B$ peak was avoided.

amounts of Spex B-10 solution so that the spike-sample mixture had ${ }^{10} \mathrm{~B} /{ }^{11} \mathrm{~B}$ ratio close to the optimum ratio of 3 . $0.2 \mathrm{~mL} 1 \%$ mannitol solution, $0.1 \mathrm{~mL} 6 \mathrm{M} \mathrm{HCl}$ and 0.5 $\mathrm{mL} 21 \mathrm{M}$ HF were added. After the vial was tightly capped, the sample was decomposed at $70^{\circ} \mathrm{C}$ for $24 \mathrm{~h}$ on a hot plate. After it cooled to room temperature, the sample was evaporated to dryness at $60^{\circ} \mathrm{C}$ for more than $17 \mathrm{~h}$ in a closed system (EvapoClean; Meinhard, USA). Subsequently, after $5 \mathrm{~mL}$ of $0.015 \mathrm{M} \mathrm{HF} / 0.15 \mathrm{M} \mathrm{HNO}_{3}$ acid mixture was added to the dried sample, the vial was capped tightly again. The vial was heated at $70^{\circ} \mathrm{C}$ for a few hours to extract boron into the solution. After it cooled to room temperature, a $1 \mathrm{~mL}$ aliquot of the supernatant was transferred into an 8-mL low density polyethylene bottles. Then $4 \mathrm{~mL}$ of the $0.015 \mathrm{M} \mathrm{HF} / 0.15 \mathrm{M} \mathrm{HNO}_{3}$ acid mixture was added to the supernatant aliquot.

For standard addition analyses, rock powder was weighed in 25-ml PFA vials. The mannitol solution, $6 \mathrm{M}$ $\mathrm{HCl}$, and $21 \mathrm{M} \mathrm{HF}$ were added similarly to the manner described for isotope dilution analyses. After decomposition, drying with EvapoClean and boron extraction steps were conducted in the same way as the method used for isotope dilution analyses; $1 \mathrm{~mL}$ of supernatant was transferred into three PE bottles. A boron standard solution was added to two of the bottles so that their respective added boron concentrations became $30 \mathrm{ppb}$ and $60 \mathrm{ppb}$. The $0.015 \mathrm{M} \mathrm{HF} / 0.15 \mathrm{M} \mathrm{HNO}_{3}$ acid mixture was added to each bottle to make the total liquid amount $5 \mathrm{~mL}$. Abundances of boron were calculated following the method described by Gotan et al. (2008). To minimize contamination of boron by the experimental environment, all chemical operations were conducted in a clean room.

\section{ICP-MS}

During this study, a $0.015 \mathrm{M} \mathrm{HF} / 0.15 \mathrm{M} \mathrm{HNO}_{3}$ acid mixture was used as a washing out solution. It usually took around $10 \mathrm{~min}$ before the background became stable. The X series-2 quadrupole ICP-MS used for this study was installed in a room where LA-ICP-MS analyses of glass bead samples were conducted. Although the $\mathrm{X}$ series-2 was not used for glass bead analyses, backgrounds on $\mathrm{m} / \mathrm{z} 10$ and 11 are high. Scanning diagrams of a 20 ppb boron standard solution and a blank solution with and without He collision gas are presented in Fig. 1. Without the He collision gas (Fig. 1(a)), background on $\mathrm{m} / \mathrm{z}=$ 11 was more than $10,000 \mathrm{cps}$. Replacements of cones and torch did not reduce the background level. Addition of He collision gas with a flow rate at $6.0 \mathrm{~mL} / \mathrm{min}$ reduced the boron sensitivity from $12000 \mathrm{cps} / \mathrm{ppb}$ (Fig. 1(a)) to $1400 \mathrm{cps} / \mathrm{ppb}$ (Fig. 1(b)). The background on $\mathrm{m} / \mathrm{z}=11$ decreased to less than $4000 \mathrm{cps}$ (Fig. 1(b)). The addition of the He collision gas did not greatly improve the signal-to-noise ratio. The addition of the He collision gas apparently accelerated the decay rate of background. Therefore, the He collision gas was used for this study. Irrespective of the collision gas use, the tailing of ${ }^{12} \mathrm{C}^{+}$ on the ${ }^{11} \mathrm{~B}$ peak was avoided.

Although a glass nebulizer gave lower backgrounds on boron isotopes and high sensitivity compared with the Teflon nebulizer, background accumulations during analyses were recognized for the glass nebulizer. Consequently, a Teflon concentric nebulizer was used for this study.

The addition of He collision gas reduced a transmission of low mass isotopes. Measured ${ }^{10} \mathrm{~B} /{ }^{11} \mathrm{~B}$ of SRM951, for which the ${ }^{10} \mathrm{~B} /{ }^{11} \mathrm{~B}$ is certified as 0.2473 , dropped from around 0.2 without $\mathrm{He}$ collision gas to around 0.1 when the He collision gas was added. The stability of ${ }^{10} \mathrm{~B} /{ }^{11} \mathrm{~B}$ of SRM951 in a day was around $1 \%$.

The influence of matrix elements on ${ }^{10} \mathrm{~B} /{ }^{11} \mathrm{~B}$ ratio was investigated using BIR-1a. Around $30 \mathrm{mg}$ of the BIR-1a was decomposed and evaporated using the method described in the preceding section. The residue was diluted with the $0.015 \mathrm{M} \mathrm{HF} / 0.15 \mathrm{M} \mathrm{HNO}_{3}$ acid mixture so that $1 \mathrm{~mL}$ of the solution contain around $1.2 \mathrm{mg}$ of initial amount of the rock, which is typical dilution factor used for the rocks with boron concentrations of more than a few ppm. The solution gave ${ }^{11} \mathrm{~B}$ signals less than $100 \mathrm{cps}$. A solution of NIST SRM951 was added to the BIR-1a solution to make the boron concentration $20 \mathrm{ppb}$. The ${ }^{10} \mathrm{~B} /$ ${ }^{11} \mathrm{~B}$ of SRM951 in the BIR-1a matrix agrees with matrixfree SRM951. The results indicated that matrix levels in this study did not modify ${ }^{10} \mathrm{~B} /{ }^{11} \mathrm{~B}$ ratios. Then, it was concluded that matrix-free SRM951 solution is useful to correct the instrumental mass bias during the boron isotopic analysis of a spike-doped sample solution.

Beryllium sensitivity under the settings described in Table 1 was about one-third of that of boron. The signal intensities of ${ }^{9} \mathrm{Be}$ in rock solutions of basalts, andesite, and granites were more than a few thousands. Conse- 


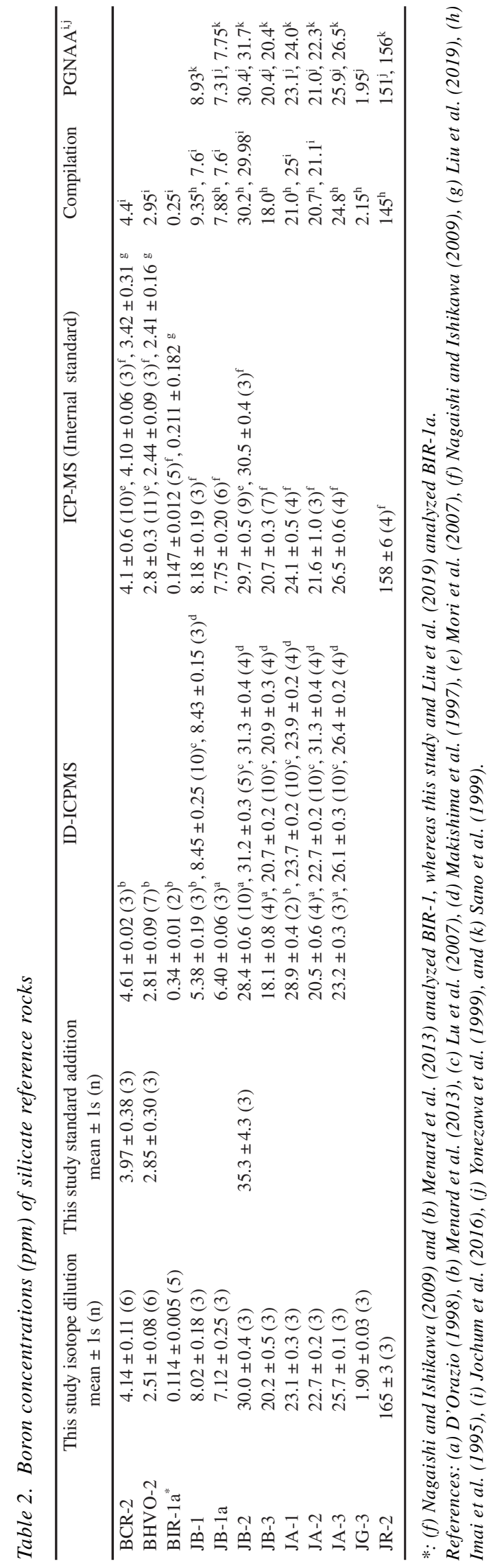

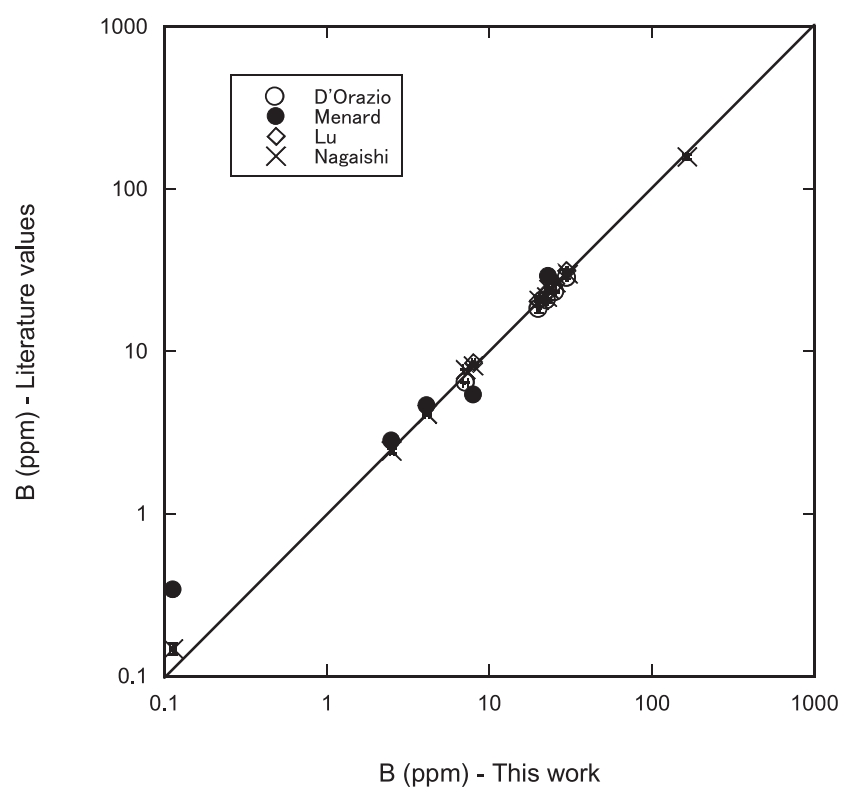

Fig. 2. Boron concentrations of geochemical reference materials analyzed using isotope dilution in this study and values from the literature. A logarithmic scale is used to clarify differences for results of BIR-1a.

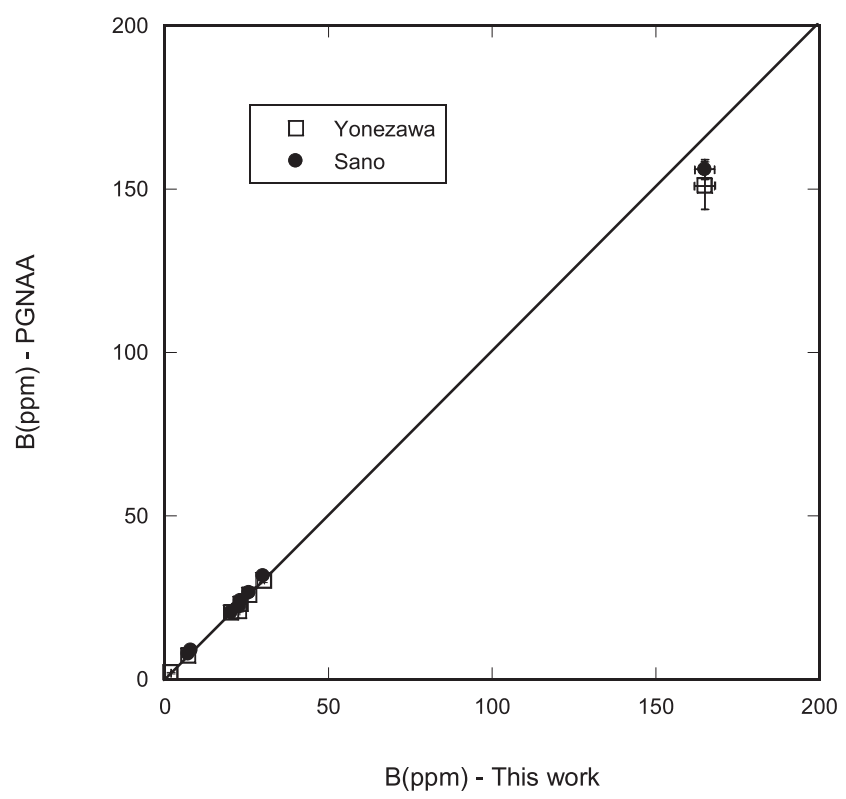

Fig. 3. Boron concentrations of geochemical reference materials analyzed using isotope dilution in this study and values by PGNAA (Sano et al., 1999; Yonezawa et al., 1999): linear scale. 
quently, applying the internal standard method described by Nagaishi and Ishikawa (2009) is difficult.

\section{RESULTS AND DISCUSSION}

\section{Boron blank and detection limit}

The boron procedural blanks operated in a closed evaporation system measured during this study varied: $0.3-7 \mathrm{ng}$ (0.01-0.2 ppm for a $30 \mathrm{mg}$ sample).

Three times the standard deviation of replicate measurements of a blank solution is usually reported as the detection limit. In this study, because of the high and changeable backgrounds, three times the standard deviation of the difference shown by a blank solution measured before and after a sample in a day is used as a detection limit of boron. The detection limit varied from 0.05 ppb to $0.1 \mathrm{ppb}$ depending on the concentrations of samples analyzed in the day.

\section{Standard addition and isotope dilution methods}

Results of boron determinations obtained using isotope dilution and standard addition methods are presented in Table 2 for three reference rocks: BCR-2, BHVO-2, and JB-2. Although the two methods yielded consistent average values, the percent one sigma relative standard deviations obtained using the standard addition method were around 10: they were 3-10 times larger than those obtained using the isotope dilution method. Gotan et al. (2008) reported results of Be determination obtained using the standard addition method. Results of repeated Be abundances of JB-2 and JA-2 yielded the percent one sigma relative standard deviations of $4.6(n=6)$ and 2.2 $(n=4) \%$, reproducibility. It was likely that high and variable backgrounds on boron isotopes deteriorated the repeatability in the standard addition analyses. Results show that the isotope dilution method yielded more reproducible results in a high-background environment.

\section{Analysis of silicate reference rocks}

Table 2 presents results of boron determination by the isotope dilution in this study along with data reported earlier. Results of prompt gamma ray neutron activation analysis are shown. Reference values of Imai et al. (1995) and Jochum et al. (2016) based on data compilations are also shown. Figure 2 presents a comparison of our results with earlier data obtained using wet chemistry analyses. D'Orazio (1998), Menard et al. (2013), and Lu et al. (2007) used isotope dilution method by ICP-MS. Our results showed deviation from those reported by D'Orazio (1998) and Menard et al. (2013). However, the deviations were around $10 \%$ for most samples. Our results agree with those reported by Lu et al. (2007). Makishima et al. (1997) analyzed boron concentrations of JB-1, JB-2, JB-3, JA1, JA-2, and JA-3 by isotope dilution with an ICP-MS.
Except for JA-2, their results agree with those reported by Lu et al. (2007). Nagaishi and Ishikawa (2009) and Mori et al. (2007) determined boron concentrations using ICP-MS internal standard method. Most of our results agreed with data presented in the two earlier reports.

The interpretation of the results of BIR-1 is not straightforward. Nagaishi and Ishikawa (2009) and Menard et al. (2013) analyzed BIR-1, whereas the present study and that of Liu et al. (2019) analyzed BIR-1a. The certificates of the two reference materials show that the two reference materials have identical chemical compositions. Our result obtained for BIR-1a showed deviation from that of Menard et al. (2013): it was close to that of Nagaishi and Ishikawa (2009), although some difference exists. Liu et al. (2019) reported a higher mean value than that reported by Nagaishi and Ishikawa (2009), although it includes rather large error.

During analyses of BIR-1a, high matrix solutions (10 $\mathrm{mg}$ of initial sample in $1 \mathrm{~mL}$ of analyzed solution) were used to compensate for the low concentration of boron in BIR-1a. Drops of background levels were found when sample solutions were aspirated, probably because of high viscosity resulting from high matrix concentration. The instability of background values might have hampered accurate analysis for the sample with low boron concentration of less than $1 \mathrm{ppm}$. Further studies must be conducted to elucidate differences of the boron concentration in this reference material. Figure 3 presents a comparison of our results with PGNAA results reported by Yonezawa et al. (1999) and by Sano et al. (1999). Differences between our results and data of PGNAA analyses were less than $10 \%$ for a wide range of boron concentrations.

\section{CONCLUDing ReMARKS}

Results of this study indicate that the isotope dilution method yielded more precise data than the standard addition method in a high background environment. Considering the difficulty of the selection of an internal standard element for boron determination, the isotope dilution method can be recommended irrespective of the background level.

Acknowledgments-The author thanks Ms. N. Hokanishi and Ms. S. Konno for their assistance during laboratory work at ERI, The University of Tokyo. Comments from Dr. K. Nagaishi and an anonymous reviewer improved the manuscript. This study was partly supported by a JSPS Grant-in-Aid for Scientific Research Grant Number JP18K03773.

\section{REFERENCES}

Chaussidon, M. and Jambon, A. (1994) Boron content and isotopic composition of oceanic basalts: Geochemical and cosmochemical implications. Earth Planet. Sci. Lett. 121, 
$277-291$.

D’Orazio, M. (1998) Boron determination in twenty one silicate rock reference materials by isotope dilution ICP-MS. Geostand. Newslett. 23, 21-29.

Gotan, K., Nakai, S. and Matsuzaki, H. (2008) Determination of ${ }^{9} \mathrm{Be}$ in geological standard samples, JA-2 and JB-2, and of ${ }^{9} \mathrm{Be}$ and ${ }^{10} \mathrm{Be}$ in a basaltic rock sample for evaluation of uncertainty involved in ${ }^{10} \mathrm{Be} /{ }^{9} \mathrm{Be}$ ratio measurements. Geochem. J. 42, 305-308.

Imai, N., Terashima, S., Itoh, S. and Ando, A. (1995) 1994 compilation of analytical data for minor and trace-elements in 17 GSJ geochemical reference samples, igneous rock series. Geostand. Newslett. 19, 135-213.

Ishikawa, T. and Nakamura, E. (1992) Boron isotope geochemistry of the oceanic crust from DSDP/ODP Hole 504B. Geochim. Cosmochim. Acta 56, 1633-1639.

Jochum, K. P., Weis, U., Schwager, B., Stoll, B., Wilson, S. A., Haug, G. H., Andreae, M. O. and Enzweiler, J. (2016) Reference values following ISO guidelines for frequently requested rock reference materials. Geostand. Geoanal. Res. 40, 333-350.

Liu, T., He, T., Shi, Q. and Ni, Q. (2019) Rapid determination of boron in 61 soil, sediment, and rock reference materials by ICP-MS. Atomic Spectro. 40, 55-62.

Lu, Y., Makishima, A. and Nakamura, E. (2007) Coprecipitation of $\mathrm{Ti}, \mathrm{Mo}, \mathrm{Sn}$ and $\mathrm{Sb}$ with fluorides and application to determination of B, Ti, $\mathrm{Zr}, \mathrm{Nb}, \mathrm{Mo}, \mathrm{Sn}, \mathrm{Sb}, \mathrm{Hf}$ and Ta by ICPMS. Chem. Geol. 236, 13-26.

Makishima, A., Nakamura, E. and Nakano, T. (1997) Determination of boron in silicate samples by direct aspiration of sample HF solutions into ICPMS. Anal. Chem. 69, 37543759.

Menard, G., Vlastélic, I., Ionov, D. A., Rose-Koga, E. F., Piro, J.-L. and Pin, C. (2013) Precise and accurate determination of boron concentration in silicate rocks by direct isotope dilution ICP-MS: Insights into the B budget of the mantle and B behavior in magmatic systems. Chem. Geol. 354, 139149.

Miyoshi, M., Shimono, M., Hasenaka, T., Sano, T., Mori, Y. and Fukuoka, T. (2010) Boron systematics of Hisatsu and Kirishima basaltic rocks from southern Kyushu, Japan. Geochem. J. 44, 359-369.

Mori, L., Gómez-Tuena, A., Cai, Y. and Goldstein, S. L. (2007) Effects of prolonged flat subduction on the Miocene magmatic record of the central Trans-Mexican Volcanic Belt. Chem. Geol. 244, 452-473.

Nagaishi, K. and Ishikawa, T. (2009) A simple method for the precise determination of boron, zirconium, niobium, hafnium and tantalum using ICP-MS and new results for rock reference samples. Geochem. J. 43, 133-141.

Ryan, J. G. and Langmuir, C. H. (1993) The systematics of boron abundances in young volcanic rocks. Geochim. Cosmochim. Acta 57, 1489-1498.

Sano, T., Fukuoka, T., Hasenaka, T., Yonezawa, C., Matsue, H. and Sawahata, H. (1998) Determination of boron content in volcanic rocks by using neutron-induced prompt $\gamma$-raycorrection of count rate fluctuation using silicon internal standard-. Radioisotopes 47, 735-744 (in Japanese with English abstract).

Sano, T., Fukuoka, T., Hasenaka, T., Yonezawa, C., Matsue, H. and Sawahata, H. (1999) Accurate and efficient determination of boron content in volcanic rocks by neutron induced prompt $\gamma$-ray analysis. J. Radioanal. Nucl. Chem. 239, 613617.

Sano, T., Hasenaka, T., Shimaoka, A., Yonezawa, C. and Fukuoka, T. (2001) Boron contents of Japan Trench sediments and Iwate basaltic lavas, Northeast Japan arc: estimation of sediment-derived fluid contribution in mantle wedge. Earth Planet. Sci. Lett. 186, 187-198.

Shinjoe, H., Orihashi, Y., Naranjo, J. A., Hirata, D., Hasenaka, T., Fukuoka, T., Sano, T. and Anma, R. (2013) Boron and other trace element constraints on the slab-derived component in Quaternary volcanic rocks from the Southern Volcanic Zone of the Andes. Geochem. J. 47, 185-199.

Yonezawa, C., Ruska, P. P., Matuse, H., Magara, M. and Adachi, T. (1999) Determination of boron in Japanese geological reference samples by neutron-induced prompt gamma-ray analysis. J. Radioanal. Nucl. Chem. 239, 571-575. 